Article

\title{
Effect of Baseline Characteristics on Cabazitaxel Treatment Duration in Patients with Metastatic Castration-Resistant Prostate Cancer: A Post Hoc Analysis of the Compassionate Use/Expanded Access Programs and CAPRISTANA Registry
}

\author{
Zafar Malik ${ }^{1, *+\dagger}{ }^{\text {, Giuseppe Di Lorenzo }}{ }^{2,3, \dagger}$, Angelika Pichler ${ }^{4}$, Ugo De Giorgi ${ }^{5}$ (D), \\ Simon Hitier ${ }^{6}$, Evelyne Ecstein-Fraisse ${ }^{7}$, Ayse Ozatilgan ${ }^{8}$ and Joan Carles ${ }^{9}$ \\ 1 Clinical Oncology, The Clatterbridge Cancer Centre NHS Foundation Trust, Wirral CH63 4JY, UK \\ 2 Department of Medicine and Health Sciences 'Vincenzo Tiberio', University of Molise, \\ 86100 Campobasso, Italy \\ 3 Medical Oncology, Tortora Hospital, 84016 Pagani, Salerno, Italy \\ 4 Department of Hematology and Oncology, Regional Hospital Hochsteiermark, 8700 Leoben, Austria \\ 5 Istituto Scientifico Romagnolo per lo Studio e la Cura dei Tumori (IRST) IRCCS, 47014 Meldola, Italy \\ Department of Biostatistics, Sanofi, 91380 Chilly-Mazarin, France \\ Medical Evidence Generation, Sanofi, 75008 Paris, France \\ Global Medical Affairs Oncology, Sanofi, Cambridge, MA 02142, USA \\ Vall d'Hebron University Hospital, Vall d'Hebron Institute of Oncology, 08035 Barcelona, Spain \\ * Correspondence: zaf.malik@nhs.net \\ $\dagger$ These authors contribute equally to this study.
}

Received: 4 February 2020; Accepted: 15 April 2020; Published: 17 April 2020

\begin{abstract}
We examined factors that may impact cabazitaxel treatment duration in a real-life setting in a compassionate use program, expanded access program, and prospective observational study in metastatic castration-resistant prostate cancer (mCRPC). Patients with mCRPC previously treated with docetaxel $(\mathrm{N}=1621)$ received cabazitaxel $25 \mathrm{mg} / \mathrm{m}^{2}$ intravenously every 3 weeks until disease progression, death, unacceptable toxicity or physician/patient decision. The median number of cabazitaxel cycles was six (range, $1-49$ ); 708 patients $(43.7 \%$ ) received $>6$ cycles. Patients receiving $>6$ cycles tended to have a better Eastern Cooperative Oncology Group performance status of $0-1$ ( $p=0.0017$ for $\leq 6$ vs. $>6$ cycles). Overall, 348 patients $(21.5 \%)$ were $\geq 75$ years of age; $139(39.9 \%)$ received $>6$ cycles. The main reason for discontinuation was disease progression; however, in patients receiving 1-2 cycles, the main reason for discontinuation was adverse events. Only 52 patients $(3.2 \%)$ progressed during cycles 1-2. Cabazitaxel was well tolerated in these studies, which included some elderly and frail patients, offering clinicians an important treatment option in the management of mCRPC. Proactive management of adverse events may allow patients to receive a higher number of cabazitaxel cycles and derive greater benefit.
\end{abstract}

Keywords: mCRPC; cabazitaxel; real-world; CUP; EAP; CAPRISTANA

\section{Introduction}

Prostate cancer is the second most commonly occurring male malignancy worldwide [1]. Early diagnosis is typically associated with a better prognosis. However, following castration-sensitive disease, approximately $10-20 \%$ of patients progress to a castration-resistant state [2]. In addition, approximately $5-21 \%$ of patients present with distant metastases at diagnosis [3,4]. 
In metastatic disease the standard treatment is surgical or chemical castration, and up to $85 \%$ of patients may respond initially [5,6]. However, nearly all patients will progress to metastatic castration-resistant prostate cancer (mCRPC) within 3 years of diagnosis [5-8].

In 2004, docetaxel was approved as a first-line treatment for mCRPC following the results of the pivotal TAX-327 Phase III trial, in which docetaxel demonstrated a significant improvement in overall survival compared with mitoxantrone [9]. Cabazitaxel is a second-generation taxane designed to overcome resistance to docetaxel and was selected for evaluation in clinical trials based on its activity in both docetaxel-sensitive and docetaxel-resistant cell lines [10]. Cabazitaxel was the first agent to demonstrate a survival benefit in the post-docetaxel setting and was approved as a second-line treatment for mCRPC in 2010 following the results of the Phase III TROPIC trial, where cabazitaxel was shown to confer a survival advantage vs. mitoxantrone (hazard ratio $0.70 ; 95 \%$ confidence interval: 0.59-0.83; $p<0.0001$ ) [11].

However, the restrictive nature of clinical trial designs seldom accounts for patients with added complicating factors such as advanced age or comorbidities. As such, real-world studies provide the platform to corroborate the findings of large Phase III trials by incorporating more diverse patient cohorts and recognizing potential unmet medical needs in order to optimize patient care [12]. Following the positive results of TROPIC and the unmet medical need the time, three studies were established to assess cabazitaxel in patients with $\mathrm{MCRPC}$ who had previously received docetaxel in a real-world setting, while providing early access to cabazitaxel in countries where commercial availability had not yet been established.

The cabazitaxel compassionate use program (CUP) [CABAZ_C_05005] and expanded access program (EAP) [NCT01254279] gave patients access to cabazitaxel for the management of post-docetaxel mCRPC and assessed the overall safety profile of cabazitaxel. CAPRISTANA (CABAZ_C_06092) was a prospective, observational study which evaluated the routine clinical use of cabazitaxel for the management of post-docetaxel mCRPC [13,14].

The objective of this current post hoc analysis was to examine the duration of cabazitaxel treatment, and factors that may impact cabazitaxel treatment duration, in a real-world setting.

\section{Results}

\subsection{Patient Population}

A total of 1621 patients were available for analysis. In CUP and EAP, 1432 patients received cabazitaxel in routine clinical practice across 41 countries: in CUP, 451 patients across 12 countries received cabazitaxel between December 2010 and May 2013; in EAP, 981 patients across 29 countries received cabazitaxel between July 2010 and December 2014 [14]. In CAPRISTANA, 189 patients across six countries received cabazitaxel in routine clinical practice between April 2012 and June 2016 (Figure 1) [13]. 


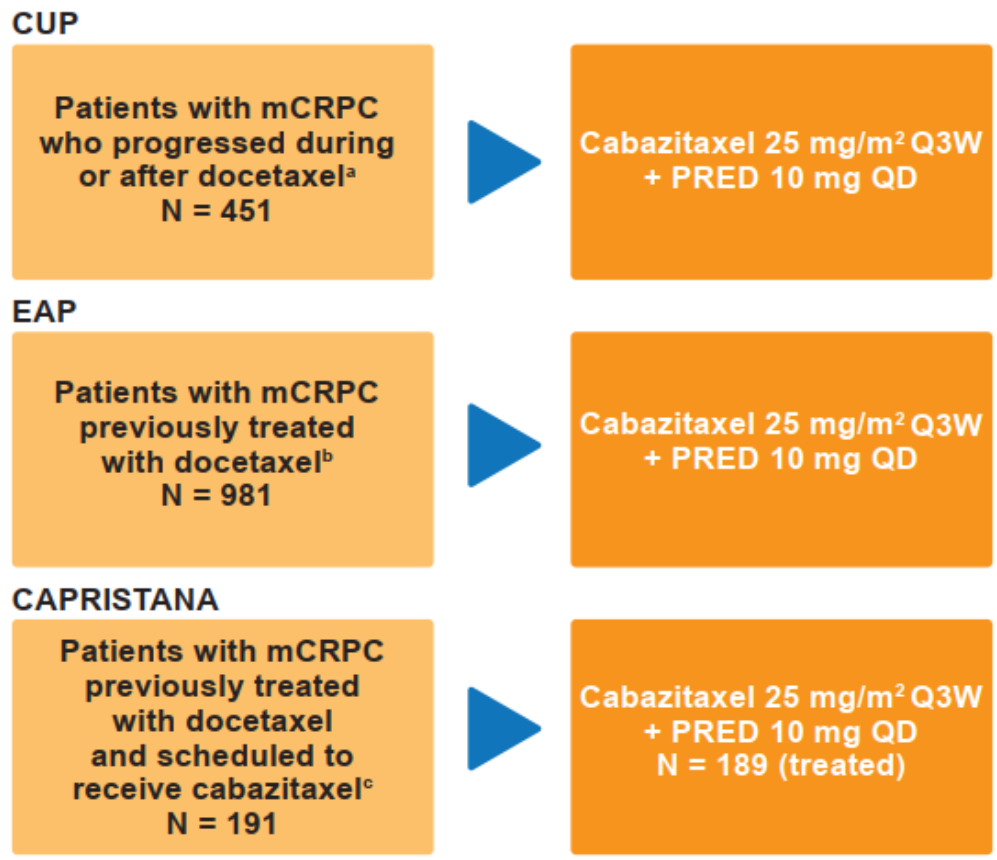

Figure 1. Study designs for the CUP, EAP and CAPRISTANA studies. ${ }^{a}$ December 2010-May 2013; ${ }^{b}$ July 2010-December 2014; ${ }^{c}$ April 2012-June 2016. CUP: compassionate use program; EAP: expanded access program; mCRPC: metastatic castration-resistant prostate cancer; PRED: prednisone or prednisolone; Q3W: once every 3 weeks; QD: once daily.

\subsection{Treatment Exposure}

Across the total population of patients, the median number of cabazitaxel cycles received was six (range, $1-49)$ with 708 patients $(43.7 \%)$ receiving $>6$ cycles and $913(56.3 \%)$ receiving $\leq 6$ cycles (Table 1 ). In total, 211 patients $(13.0 \%)$ received $\geq 11$ cycles of cabazitaxel; among these patients the median number of cabazitaxel cycles received was 14 (range, 11-49). Of note, in some countries included in the CUP/EAP/CAPRISTANA studies, patients did not receive $>10$ cabazitaxel cycles (10/47 countries; Luxembourg, Bangladesh, Peru, Singapore, Germany, India, Philippines, Poland, Serbia and Taiwan). For a list of the maximum number of cabazitaxel cycles received in each country, please see the online Supplementary Materials (Table S1).

Table 1. Cabazitaxel treatment and granulocyte-colony stimulating factor (G-CSF) use according to the number of cabazitaxel treatment cycles received across the CUP/EAP and CAPRISTANA studies.

\begin{tabular}{ccc}
\hline & \multicolumn{2}{c}{ CUP/EAP/CAPRISTANA } \\
\cline { 2 - 3 } Treatment Characteristics & \multicolumn{2}{c}{$\mathbf{N}=\mathbf{1 6 2 1}$} \\
\cline { 2 - 3 } & \multicolumn{2}{c}{ Cabazitaxel Cycles Received } \\
\cline { 2 - 3 } & $\mathbf{n}=\mathbf{9 1 3}$ & $\mathbf{6}$ \\
& $4(1-6)$ & $\mathbf{n}=\mathbf{7 0 8}$ \\
\hline Median cabazitaxel cycles, n (range) & $2.8(1-6)$ & $10(7-49)$ \\
\hline Median duration of cabazitaxel & & $6.9(5-35)$ \\
exposure, months (range) & $\mathrm{n}=499(54.7)$ & $\mathrm{n}=380(53.7)$ \\
G-CSF during Cycle 1, $\mathrm{n}(\%)$ & $385(42.2)$ & $314(44.4)$ \\
Prophylactic & $69(7.6)$ & $33(4.7)$ \\
Therapeutic & $45(4.9)$ & $33(4.7)$ \\
Both & &
\end{tabular}


Table 1. Cont.

\begin{tabular}{|c|c|c|c|}
\hline \multirow{4}{*}{ Treatment Characteristics } & \multicolumn{3}{|c|}{ CUP/EAP/CAPRISTANA } \\
\hline & \multicolumn{3}{|c|}{$N=1621$} \\
\hline & \multicolumn{3}{|c|}{ Cabazitaxel Cycles Received } \\
\hline & $\begin{aligned} & \leq 6 \\
n & =913\end{aligned}$ & \multicolumn{2}{|r|}{$\begin{aligned} & >6 \\
n & =708\end{aligned}$} \\
\hline & \multicolumn{3}{|c|}{ Cabazitaxel cycles received } \\
\hline & $\begin{array}{c}\quad \leq 4 \\
\mathrm{n}=551\end{array}$ & \multicolumn{2}{|r|}{$\begin{array}{c}>4 \\
\mathrm{n}=1070\end{array}$} \\
\hline Median cabazitaxel cycles, $\mathrm{n}$ (range) & $3(1-4)$ & \multicolumn{2}{|r|}{$8(5-49)$} \\
\hline $\begin{array}{l}\text { Median duration of cabazitaxel } \\
\text { exposure, months (range) }\end{array}$ & $2.1(1-5)$ & \multicolumn{2}{|r|}{$5.8(3-35)$} \\
\hline G-CSF during Cycle 1, n (\%) & $\mathrm{n}=297(53.9)$ & \multicolumn{2}{|r|}{$\mathrm{n}=582(54.4)$} \\
\hline Prophylactic & $224(40.7)$ & \multicolumn{2}{|r|}{$475(44.4)$} \\
\hline Therapeutic & $43(7.8)$ & \multicolumn{2}{|r|}{$59(5.5)$} \\
\hline \multirow[t]{3}{*}{ Both } & $30(5.4)$ & & $48(4.5)$ \\
\hline & \multicolumn{3}{|c|}{ Cabazitaxel cycles received } \\
\hline & $\begin{array}{c}1-2 \\
n=237\end{array}$ & $\begin{array}{c}3-10 \\
n=1173\end{array}$ & $\begin{aligned} & \geq 11 \\
n & =211\end{aligned}$ \\
\hline Median cabazitaxel cycles, n (range) & $1(1-2)$ & $6(3-10)$ & $14(11-49)$ \\
\hline $\begin{array}{l}\text { Median duration of cabazitaxel } \\
\text { exposure, months (range) }\end{array}$ & $0.7(1-2)$ & $4.3(2-11)$ & $10.3(8-35)$ \\
\hline G-CSF during Cycle 1, n (\%) & $\mathrm{n}=141(59.5)$ & $\mathrm{n}=632(53.9)$ & $\mathrm{n}=106(50.2)$ \\
\hline Prophylactic & $100(42.2)$ & $515(43.9)$ & $84(39.8)$ \\
\hline Therapeutic & $25(10.5)$ & $66(5.6)$ & $11(5.2)$ \\
\hline Both & $16(6.8)$ & $51(4.3)$ & $11(5.2)$ \\
\hline
\end{tabular}

CUP: compassionate use program; EAP: expanded access program; G-CSF: granulocyte-colony stimulating factor.

\subsection{Granulocyte-Colony Stimulating Factor (G-CSF) Use for Neutropenia}

Prophylactic and therapeutic use of G-CSF was allowed at the physicians' discretion. For the CUP and EAP studies, the protocols stated that primary prophylaxis with G-CSF (defined as use during Cycle 1; secondary prophylaxis defined as use in any subsequent cycle) should be considered in patients with high-risk clinical features that may predispose them to increased complications from prolonged neutropenia ( $\geq 65$ years of age, poor performance status, previous episodes of febrile neutropenia, extensive prior radiation ports, poor nutritional status, or other serious comorbidities). G-CSF was administered during Cycle 1 in $54.2 \%$ of patients (Table 1 ).

\subsection{Patient Characteristics That May Impact Cabazitaxel Treatment Duration}

Baseline demographics and clinical characteristics for each treatment group defined by the number of cabazitaxel cycles received are summarized in Tables 2-4. This analysis investigated a large population of patients $(\mathrm{N}=1621)$, with a number of patients presenting with aggressive disease characteristics at baseline. For example, lung metastases, liver metastases and other visceral/soft tissue metastases were present in $11.0 \%, 9.3 \%$ and $4.3 \%$ of patients at baseline, respectively, a short median time from mCRPC diagnosis was observed (1.7-1.8 years), and patients had received a high number of prior docetaxel cycles at last administration (medians ranging between 7 and 10 cycles) with the median cumulative dose of the last docetaxel administration ranging between 600 and $750 \mathrm{mg} / \mathrm{m}^{2}$. 
Table 2. Patient baseline characteristics according to the number of cabazitaxel treatment cycles received ( $\leq 6$ vs. $>6$ cycles) across the CUP/EAP and CAPRISTANA studies.

\begin{tabular}{|c|c|c|c|}
\hline \multirow{3}{*}{ Patient Baseline Characteristics } & \multicolumn{3}{|c|}{$\begin{array}{l}\text { CUP/EAP/CAPRISTANA } \\
\qquad \mathrm{N}=1621\end{array}$} \\
\hline & \multicolumn{2}{|c|}{ Cabazitaxel Cycles Received } & \multirow[b]{2}{*}{$p$ Value } \\
\hline & $\begin{aligned} & \leq 6 \\
n & =913\end{aligned}$ & $\begin{aligned} & >6 \\
n & =708\end{aligned}$ & \\
\hline Median age, years (range) & $68.0(42-89)$ & $68.0(43-89)$ & 0.0855 \\
\hline $\begin{array}{l}\text { Age, } \mathrm{n}(\%) \\
<65 \text { years } \\
65-75 \text { years } \\
\geq 75 \text { years }\end{array}$ & $\begin{array}{l}271(29.7) \\
433(47.4) \\
209(22.9)\end{array}$ & $\begin{array}{l}230(32.5) \\
339(47.9) \\
139(19.6)\end{array}$ & 0.2227 \\
\hline $\begin{array}{l}\text { ECOG PS, n (\%) } \\
0-1 \\
2^{\mathrm{a}}\end{array}$ & $\begin{array}{l}\mathrm{n}=912 \\
816(89.5) \\
96(10.5)\end{array}$ & $\begin{array}{l}\mathrm{n}=708 \\
665(93.9) \\
43(6.1)\end{array}$ & 0.0015 \\
\hline $\begin{array}{l}\text { Frailty, } \mathrm{n}(\%) \\
\text { ECOG PS }<2 \text { and } \leq 75 \text { years } \\
\text { ECOG PS }<2 \text { and }>75 \text { years } \\
\text { ECOG PS } \geq 2 \text { and } \leq 75 \text { years } \\
\text { ECOG PS } \geq 2 \text { and }>75 \text { years }\end{array}$ & $\begin{array}{l}\mathrm{n}=912 \\
660(72.4) \\
156(17.1) \\
73(8.0) \\
23(2.5)\end{array}$ & $\begin{array}{c}\mathrm{n}=708 \\
566(79.9) \\
99(14.0) \\
30(4.2) \\
13(1.8)\end{array}$ & 0.0016 \\
\hline Median time from prostate cancer diagnosis, years (range) & $4.5(0-22)$ & $4.7(0-20)$ & 0.0659 \\
\hline Median time from mCRPC diagnosis, years (range) & $1.7(0-14)$ & $1.8(0-12)$ & 0.1298 \\
\hline Median docetaxel cycles at last administration, $\mathrm{n}$ (range) & $7(1-69)$ & $8(1-58)$ & $<0.0001$ \\
\hline $\begin{array}{l}\text { Median cumulative dose of last docetaxel administration, } \\
\qquad \mathrm{mg} / \mathrm{m}^{2} \text { (range) }\end{array}$ & $600(50-5145)$ & $675(105-8700)$ & 0.0005 \\
\hline $\begin{array}{c}\text { Metastatic sites, n (\%) } \\
\text { Bone } \\
\text { Regional lymph nodes } \\
\text { Lungs } \\
\text { Liver } \\
\text { Visceral, other soft tissue }\end{array}$ & $\begin{array}{c}\mathrm{n}=912 \\
829(90.8) \\
282(30.9) \\
111(12.2) \\
105(11.5) \\
47(5.1)\end{array}$ & $\begin{array}{c}\mathrm{n}=707 \\
630(89.0) \\
214(30.2) \\
68(9.6) \\
46(6.5) \\
23(3.2)\end{array}$ & - \\
\hline $\begin{array}{c}\text { Number of metastatic sites, } \mathrm{n}(\%) \\
0 \\
1 \\
\geq 2\end{array}$ & $\begin{array}{c}\mathrm{n}=913 \\
1(0.1) \\
298(32.6) \\
614(67.3)\end{array}$ & $\begin{array}{c}\mathrm{n}=708 \\
1(0.1) \\
272(38.4) \\
435(61.4)\end{array}$ & 0.0254 \\
\hline $\begin{array}{c}\text { Pain at baseline (CAPRISTANA study only), n (\%) } \\
\text { None } \\
\text { Moderate } \\
\text { Severe }\end{array}$ & $\begin{array}{c}\mathrm{n}=86 \\
15(17.4) \\
63(73.3) \\
8(9.3)\end{array}$ & $\begin{array}{c}\mathrm{n}=68 \\
18(26.5) \\
47(69.1) \\
3(4.4)\end{array}$ & 0.2457 \\
\hline
\end{tabular}

\footnotetext{
${ }^{\mathrm{a}}$ Includes one patient with ECOG PS 3 receiving $\leq 6$ cabazitaxel cycles. CUP: compassionate use program; EAP: expanded access program; ECOG PS: Eastern Cooperative Oncology Group performance status; mCRPC: metastatic castration-resistant prostate cancer.
}

Some baseline characteristics differed across the treatment groups defined according to the number of cabazitaxel cycles received, suggesting some baseline parameters may impact the duration of cabazitaxel treatment ( $\leq 6$ vs. $>6$ cycles, Table $2 ; \leq 4$ vs. $>4$ cycles, Table $3 ; 1-2$ vs. $3-10$ vs. $\geq 11$ cycles, Table 4), including Eastern Cooperative Oncology Group performance status (ECOG PS), frailty, number of metastatic sites (referring to organ systems), and prior docetaxel treatment duration. More patients in the treatment groups receiving fewer cabazitaxel cycles tended to have a poorer ECOG PS compared with the treatment groups that received more cabazitaxel cycles (Tables 2-4). In total, $21.5 \%$ of patients (348/1621) were $\geq 75$ years of age and of these patients, $139(40 \%)$ received $>6$ cabazitaxel cycles and $44(12.6 \%)$ received $\geq 11$ cabazitaxel cycles. Among frail patients (defined 
as patients with ECOG PS $\geq 2$ and $>75$ years of age; $n=36), 13$ patients $(36.1 \%)$ received $>6$ cycles, two patients $(5.6 \%)$ received $\geq 11$ cycles and 14 patients $(38.9 \%)$ received only $1-2$ cycles of cabazitaxel. In multivariate analyses ECOG PS, the number of metastatic sites and prior exposure to docetaxel were all independently associated with the number of cabazitaxel treatment cycles received (Table S2).

Table 3. Patient baseline characteristics according to the number of cabazitaxel treatment cycles received ( $\leq 4$ vs. $>4$ cycles) across the CUP/EAP and CAPRISTANA studies.

\begin{tabular}{|c|c|c|c|}
\hline \multirow{3}{*}{ Patient Baseline Characteristics } & \multicolumn{3}{|c|}{$\begin{array}{c}\text { CUP/EAP/CAPRISTANA } \\
\mathrm{N}=1621\end{array}$} \\
\hline & \multicolumn{2}{|c|}{ Cabazitaxel Cycles Received } & \multirow[b]{2}{*}{$p$ Value } \\
\hline & $\begin{aligned} & \leq 4 \\
n & =551\end{aligned}$ & $\begin{array}{c}>4 \\
n=1070\end{array}$ & \\
\hline Median age, years (range) & $69.0(42-89)$ & $68.0(42-89)$ & 0.2033 \\
\hline $\begin{array}{l}\text { Age, } \mathrm{n}(\%) \\
<65 \text { years } \\
65-75 \text { years } \\
\geq 75 \text { years }\end{array}$ & $\begin{array}{l}165(29.9) \\
258(46.8) \\
128(23.2)\end{array}$ & $\begin{array}{l}336(31.4) \\
514(48.0) \\
220(20.6)\end{array}$ & 0.4562 \\
\hline $\begin{array}{l}\text { ECOG PS, n }(\%) \\
0-1 \\
2^{\mathrm{a}}\end{array}$ & $\begin{array}{l}\mathrm{n}=550 \\
476(86.5) \\
74(13.5)\end{array}$ & $\begin{array}{c}\mathrm{n}=1070 \\
1005(93.9) \\
65(6.1)\end{array}$ & $<0.0001$ \\
\hline $\begin{array}{l}\text { Frailty, } \mathrm{n}(\%) \\
\text { ECOG PS }<2 \text { and } \leq 75 \text { years } \\
\text { ECOG PS }<2 \text { and }>75 \text { years } \\
\text { ECOG PS } \geq 2 \text { and } \leq 75 \text { years } \\
\text { ECOG PS } \geq 2 \text { and }>75 \text { years }\end{array}$ & $\begin{array}{l}\mathrm{n}=550 \\
386(70.2) \\
90(16.4) \\
56(10.2) \\
18(3.3)\end{array}$ & $\begin{array}{l}\mathrm{n}=1070 \\
840(78.5) \\
165(15.4) \\
47(4.4) \\
18(1.7)\end{array}$ & $<0.0001$ \\
\hline Median time from prostate cancer diagnosis, years (range) & $4.6(0-22)$ & $4.7(0-20)$ & 0.1603 \\
\hline Median time from mCRPC diagnosis, years (range) & $1.7(0-11)$ & $1.8(0-14)$ & 0.1359 \\
\hline Median docetaxel cycles at last administration, $\mathrm{n}$ (range) & $7(1-69)$ & $8(1-68)$ & 0.0061 \\
\hline $\begin{array}{l}\text { Median cumulative dose of last docetaxel administration, } \\
\qquad \mathrm{mg} / \mathrm{m}^{2} \text { (range) }\end{array}$ & $600(50-5145)$ & $675(50-8700)$ & 0.0063 \\
\hline $\begin{array}{c}\text { Metastatic sites, n (\%) } \\
\text { Bone } \\
\text { Regional lymph nodes } \\
\text { Lungs } \\
\text { Liver } \\
\text { Visceral, other soft tissue }\end{array}$ & $\begin{array}{c}\mathrm{n}=550 \\
497(90.2) \\
173(31.4) \\
80(14.5) \\
75(13.6) \\
29(5.3)\end{array}$ & $\begin{array}{c}\mathrm{n}=106 \\
962(89.9) \\
323(30.2) \\
99(9.3) \\
76(7.1) \\
41(3.8)\end{array}$ & - \\
\hline $\begin{array}{c}\text { Number of metastatic sites, } \mathrm{n}(\%) \\
0 \\
1 \\
\geq 2\end{array}$ & $\begin{array}{c}\mathrm{n}=551 \\
1(0.2) \\
171(31.0) \\
379(68.8)\end{array}$ & $\begin{array}{l}\mathrm{n}=1070 \\
1(<0.1) \\
399(37.3) \\
670(62.6)\end{array}$ & 0.0190 \\
\hline $\begin{array}{c}\text { Pain at baseline (CAPRISTANA study only), n (\%) } \\
\text { None } \\
\text { Moderate } \\
\text { Severe }\end{array}$ & $\begin{array}{l}\mathrm{n}=48 \\
6(12.5) \\
36(75.0) \\
6(12.5)\end{array}$ & $\begin{array}{l}\mathrm{n}=106 \\
27(25.5) \\
74(69.8) \\
5(4.7)\end{array}$ & 0.0737 \\
\hline
\end{tabular}

\footnotetext{
${ }^{a}$ Includes one patient with ECOG PS 3 receiving $\leq 4$ cabazitaxel cycles. CUP: compassionate use program; EAP: expanded access program; ECOG PS: Eastern Cooperative Oncology Group performance status; mCRPC: metastatic castration-resistant prostate cancer.
} 
Table 4. Patient baseline characteristics according to the number of cabazitaxel treatment cycles received (1-2 vs. $3-10$ vs. $\geq 11$ cycles) across the CUP/EAP and CAPRISTANA studies.

\begin{tabular}{|c|c|c|c|c|}
\hline \multirow{3}{*}{ Patient Baseline Characteristics } & \multicolumn{4}{|c|}{$\begin{array}{l}\text { CUP/EAP/CAPRISTANA } \\
\qquad \mathrm{N}=1621\end{array}$} \\
\hline & \multicolumn{3}{|c|}{ Cabazitaxel Cycles Received } & \multirow[b]{2}{*}{$p$ Value } \\
\hline & $\begin{array}{c}1-2 \\
n=237\end{array}$ & $\begin{array}{c}3-10 \\
n=1173\end{array}$ & $\begin{aligned} & \geq 11 \\
n & =211\end{aligned}$ & \\
\hline Median age, years (range) & $70.0(42-89)$ & $68.0(42-89)$ & $68.0(49-87)$ & 0.0114 \\
\hline $\begin{array}{c}\text { Age, } \mathrm{n}(\%) \\
<65 \text { years } \\
65-75 \text { years } \\
\geq 75 \text { years }\end{array}$ & $\begin{array}{c}64(27.0) \\
103(43.5) \\
70(29.5)\end{array}$ & $\begin{array}{l}377(32.1) \\
562(47.9) \\
234(19.9)\end{array}$ & $\begin{array}{c}60(28.4) \\
107(50.7) \\
44(20.9)\end{array}$ & 0.0177 \\
\hline ECOG PS, n (\%) & $\mathrm{n}=237$ & $\mathrm{n}=1172$ & $\mathrm{n}=211$ & \\
\hline $0-1$ & $197(83.1)$ & $1082(92.3)$ & $202(95.7)$ & 0.0001 \\
\hline $2^{a}$ & $40(16.9)$ & $90(7.7)$ & $9(4.3)$ & \\
\hline Frailty, n (\%) & $\mathrm{n}=237$ & $\mathrm{n}=1172$ & $\mathrm{n}=211$ & \\
\hline ECOG PS $<2$ and $\leq 75$ years & $149(62.9)$ & $906(77.3)$ & $171(81.0)$ & \\
\hline ECOG PS $<2$ and $>75$ years & $48(20.3)$ & $176(15.0)$ & $31(14.7)$ & $<0.0001$ \\
\hline ECOG PS $\geq 2$ and $\leq 75$ years & $26(11.0)$ & $70(6.0)$ & $7(3.3)$ & \\
\hline ECOG PS $\geq 2$ and $>75$ years & $14(5.9)$ & $20(1.7)$ & $2(0.9)$ & \\
\hline $\begin{array}{l}\text { Median time from prostate cancer diagnosis, years } \\
\text { (range) }\end{array}$ & $4.9(1-22)$ & $4.4(0-20)$ & $5.5(1-18)$ & 0.0002 \\
\hline Median time from mCRPC diagnosis, years (range) & $1.8(0-10)$ & $1.7(0-14)$ & $1.8(0-10)$ & 0.2483 \\
\hline $\begin{array}{l}\text { Median docetaxel cycles at last administration, } \mathrm{n} \\
\text { (range) }\end{array}$ & $8(1-34)$ & $8(1-69)$ & $10(2-49)$ & $<0.0001$ \\
\hline $\begin{array}{l}\text { Median cumulative dose of last docetaxel } \\
\text { administration, } \mathrm{mg} / \mathrm{m}^{2} \text { (range) }\end{array}$ & $\begin{array}{c}600 \\
(50-2850)\end{array}$ & $\begin{array}{c}610.6 \\
(50-8700)\end{array}$ & $\begin{array}{c}750 \\
(120-2830) \\
\end{array}$ & $<0.0123$ \\
\hline Metastatic sites, n (\%) & $\mathrm{n}=236$ & $\mathrm{n}=1173$ & $\mathrm{n}=210$ & \\
\hline Bone & $211(89.0)$ & $1062(90.5)$ & $186(88.2)$ & \\
\hline Regional lymph nodes & $75(31.6)$ & $361(30.8)$ & $60(28.4)$ & - \\
\hline Lungs & $42(17.7)$ & $119(10.1)$ & $18(8.5)$ & - \\
\hline Liver & $39(16.5)$ & $101(8.6)$ & $11(5.2)$ & \\
\hline Visceral, other soft tissue & $9(3.8)$ & $54(4.6)$ & $7(3.3)$ & \\
\hline Number of metastatic sites, n (\%) & $\mathrm{n}=237$ & $\mathrm{n}=1173$ & $\mathrm{n}=211$ & \\
\hline 0 & $1(0.4)$ & 0 & $1(0.5)$ & \\
\hline 1 & $71(30.0)$ & $415(35.4)$ & $84(39.8)$ & 0.0203 \\
\hline$\geq 2$ & $165(69.6)$ & $758(64.6)$ & $126(59.7)$ & \\
\hline Pain at baseline (CAPRISTANA study only), n (\%) & $\mathrm{n}=8$ & $\mathrm{n}=127$ & $\mathrm{n}=19$ & \\
\hline None & $3(37.5)$ & $24(18.9)$ & $6(31.6)$ & ח2520 \\
\hline Moderate & $4(50.0)$ & $93(73.2)$ & $13(68.4)$ & $0.2 \angle 60$ \\
\hline Severe & $1(12.5)$ & $10(7.9)$ & 0 & \\
\hline
\end{tabular}

${ }^{a}$ Includes one patient with ECOG PS 3 receiving 1-2 cabazitaxel cycles. CUP: compassionate use program; EAP: expanded access program; ECOG PS: Eastern Cooperative Oncology Group performance status; mCRPC: metastatic castration-resistant prostate cancer.

\subsection{Disease Progression during the First Two Cycles of Treatment}

Across the CUP/EAP and CAPRISTANA studies, only 3.2\% of patients (52/1621) progressed during the first two cycles of cabazitaxel treatment; of these patients, 19 had visceral metastases (lungs, liver, and other visceral/soft tissue) and 33 had other metastatic sites at baseline. 


\subsection{Reasons for Discontinuation According to Cabazitaxel Treatment Duration}

The reasons for treatment discontinuation differed between patients receiving $\leq 6 \mathrm{vs}$. $>6$ cabazitaxel cycles, $\leq 4$ vs. $>4$ cycles and $1-2$ vs. $3-10$ vs. $\geq 11$ cycles $(p<0.0001)$ (Figure 2$)$. The main reason for discontinuation was disease progression across all treatment groups defined by the number of cabazitaxel cycles received, with one exception: in patients receiving 1-2 cycles of cabazitaxel the main reason for discontinuation was adverse events (AEs). Patient request to discontinue treatment was low across all treatment groups and investigator decision to discontinue treatment increased as the treatment duration increased. Among frailer patients (ECOG PS $\geq 2$ and $>75$ years of age; $n=36$ ), AEs appeared to be the main reason for treatment discontinuation.
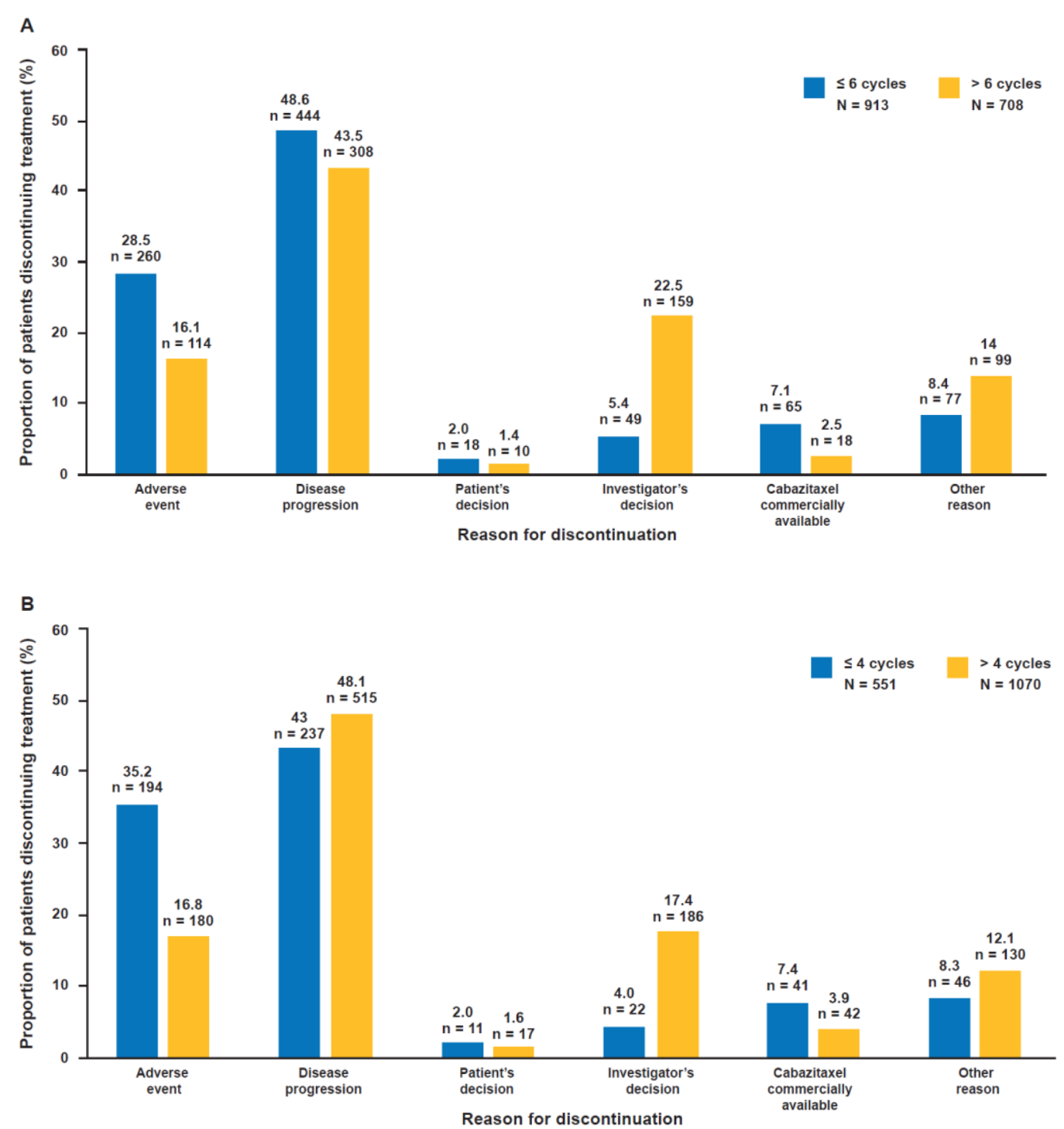

Figure 2. Cont. 


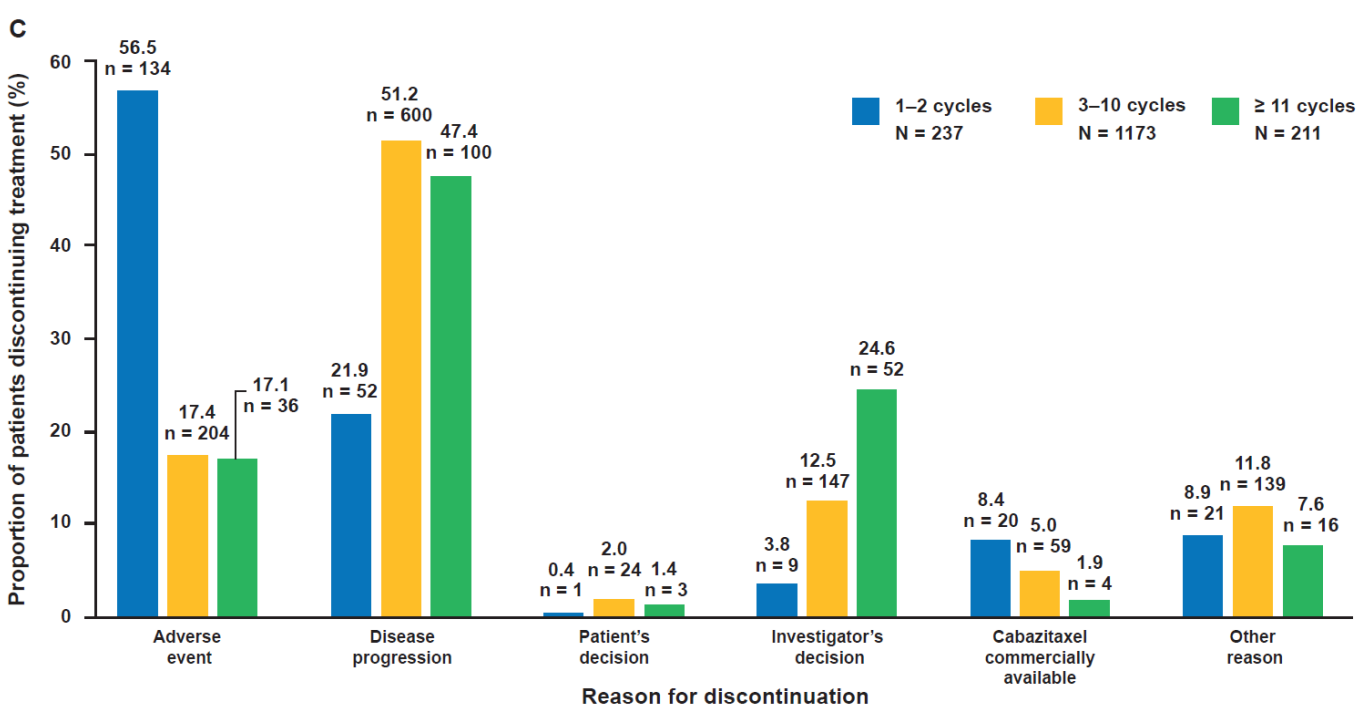

Figure 2. Reasons for treatment discontinuation according to the number of cabazitaxel treatment cycles received across the CUP/EAP and CAPRISTANA studies: $($ A) $\leq 6$ cycles vs. $>6$ cycles; $($ B $) \leq 4$ cycles vs. $>4$ cycles; (C) 1-2 cycles vs. $3-10$ cycles vs. $\geq 11$ cycles. CUP: compassionate use program; EAP: expanded access program.

In patients receiving $\leq 6(\mathrm{n}=23)$ vs. $>6(\mathrm{n}=13)$ cycles, $12(52.2 \%)$ vs. $5(38.5 \%)$ patients discontinued due to AEs and $7(30.4 \%)$ vs. $3(23.1 \%)$ patients discontinued due to disease progression, respectively. In patients receiving $\leq 4(\mathrm{n}=18)$ vs. $>4(\mathrm{n}=18)$ cycles, $11(61.1 \%)$ vs. $6(33.3 \%)$ patients discontinued due to AEs and $4(22.2 \%)$ vs. $6(33.3 \%)$ patients discontinued due to disease progression, respectively. In patients receiving $1-2(\mathrm{n}=14)$ vs. $3-10(\mathrm{n}=20)$ vs. $\geq 11(\mathrm{n}=2)$ cycles, $9(64.3 \%)$ vs. $7(35.0 \%)$ vs. $1(50.0 \%)$ patient discontinued due to AEs and $3(21.4 \%)$ vs. $7(35.0 \%)$ vs. 0 patients discontinued due to disease progression, respectively.

\section{Discussion}

Cabazitaxel may offer clinicians a useful and important treatment option in the management of patients with mCRPC. This post hoc analysis of real-world data from the CUP/EAP and CAPRISTANA studies investigated a large, global patient population $(\mathrm{N}=1621)$, with a number of patients presenting with aggressive disease characteristics at baseline. The patients enrolled in this pooled analysis were similar to the patient populations of the Phase III TROPIC and PROSELICA trials assessing cabazitaxel in patients with mCRPC post-docetaxel [11,15]. Cabazitaxel was well tolerated in this pooled analysis, which included a proportion of elderly patients, with many patients receiving a high number of treatment cycles. Some baseline characteristics (ECOG PS, frailty, metastatic sites, prior docetaxel treatment duration) may impact cabazitaxel treatment duration with the data suggesting that patients with a poorer prognosis, more aggressive disease or poor ECOG PS, tended to receive fewer cabazitaxel cycles. Multivariate analyses suggested that ECOG PS, number of metastatic sites and prior docetaxel treatment were all associated with cabazitaxel treatment duration.

During the first two cabazitaxel treatment cycles, the main reason for treatment discontinuation was AEs. However, during later cycles, more patients discontinued treatment due to disease progression. This may be due to a higher disease burden present at baseline and suggests that proactive management of AEs early in the course of cabazitaxel treatment may allow patients to go on to receive a higher number of cabazitaxel cycles and derive a greater benefit.

The CUP/EAP/CAPRISTANA studies included a proportion of patients that were elderly and/or frail (ECOG PS $\geq 2$ and $>75$ years of age). Among the frailer patients $36 \%$ received $>6$ cycles and among patients $\geq 75$ years of age, $40 \%$ received $>6$ cycles and $13 \%$ received $>0$ cycles. Treating elderly patients in the clinic often represents a challenge due to age-related comorbidities and weakening 
organ function, therefore, chemotherapy is often avoided, even in the case of fit, elderly patients [16]. In mCRPC, elderly patients represent a significant proportion of patients being treated in clinical practice and they should have access to treatments that may prolong their survival and improve their outcome [16]. Notably, in the current analysis, amongst the fit, elderly patients (ECOG PS $<2$ and $>75$ years of age), $39 \%$ received $>6$ cycles and $12 \%$ received $>10$ cycles of cabazitaxel.

Elderly patients are more likely to experience certain AEs with cabazitaxel, particularly neutropenia and febrile neutropenia $[17,18]$. In the TROPIC and PROSELICA trials, the rates of neutropenia, fatigue, asthenia, pyrexia, dizziness, urinary tract infection, diarrhea and dehydration were higher amongst patients who were $\geq 65$ years of age $[11,15,18]$. The main reason for treatment discontinuation in the elderly/frail patients in this analysis was AEs. However, with active AE management, elderly patients may be able to receive a greater number of cabazitaxel cycles, as shown in this post hoc analysis. No specific dose adjustment of cabazitaxel is recommended in elderly patients as no significant difference in cabazitaxel pharmacokinetics between patients $<65$ years $(n=100)$ and older $(n=70)$ has been observed. [17,18]. Furthermore, in the TROPIC study, there was no overall difference in cabazitaxel effectiveness between patients $\geq 65$ years of age and younger $[11,18]$. Some studies have assessed, or are currently assessing, different cabazitaxel dosing schedules for elderly patients (e.g., weekly $8-10 \mathrm{mg} / \mathrm{m}^{2}$; twice-weekly $16 \mathrm{mg} / \mathrm{m}^{2}$ on Day 1 and 15 of a 4-week cycle) [19-21], however, dose modifications based on the age of the patient alone are not recommended [17,18]. An individual approach should be taken with management driven by a patient's physiological age and functional status rather than their chronological age. [16] The International Society of Geriatric Oncology has developed guidelines for the treatment of elderly patients with prostate cancer which considers comorbidities, health status, dependence status, and nutritional status [16,22].

Other studies support this current post hoc analysis suggesting that cabazitaxel is well-tolerated in a real-world setting regardless of age [16,23-26]. From previous analyses of the CUP/EAP/CAPRISTANA data the most frequently reported treatment emergent AEs (TEAEs) were consistent with the safety profile of cabazitaxel reported in the TROPIC and PROSELICA studies [11,13-15]. Some studies have suggested that prophylactic use of G-CSF appears to be more frequent in elderly patients and may improve tolerability in elderly patients receiving cabazitaxel, particularly when given at Cycle 1 [16,27]. Prophylactic G-CSF was not allowed during Cycle 1 in the PROSELICA and TROPIC studies but was permitted in the CUP/EAP/CAPRISTANA studies; this may, in part, explain the lower rates of neutropenia observed in these studies [11,13-15]. This analysis showed that hematological AEs can be effectively managed and reduced when G-CSF is used.

Of note, at the time of the CUP/EAP/CAPRISTANA studies the recommended dosing for cabazitaxel was $25 \mathrm{mg} / \mathrm{m}^{2}$ every 3 weeks. In light of the PROSELICA data, where cabazitaxel $20 \mathrm{mg} / \mathrm{m}^{2}$ dosing was proven to be non-inferior to $25 \mathrm{mg} / \mathrm{m}^{2}$ in terms of overall survival, the Food and Drug Administration approved the lower dose of cabazitaxel for the treatment of mCRPC, with $25 \mathrm{mg} / \mathrm{m}^{2}$ recommended for select patients at the physician's discretion $[15,18]$.

It is important to note that the CUP, EAP and CAPRISTANA studies are associated with certain limitations. As the studies were conducted across many countries, the impact of regional variation should be considered. For example, in some countries, longer treatment duration and a higher number of treatment cycles were considered routine practice and undertaken more often than in other countries. In addition, variation in regional guidelines for the prophylactic and therapeutic use of G-CSF for neutropenia may have influenced safety outcomes. Furthermore, there will have been variability among the sites regarding use of electronic records, which could potentially lead to missing data and incomplete representation of cabazitaxel use in the clinical setting. Finally, the median time from mCRPC diagnosis currently experienced in clinical practice is potentially longer than when these studies were undertaken due to the availability of new antiandrogen treatments, such as abiraterone and enzalutamide, which were not utilized at the time of these studies and are now being used earlier in the course of the disease. 
In patients with mCRPC who have received prior docetaxel, treatment options include cabazitaxel, abiraterone or enzalutamide, which have all proven effective in the post-docetaxel setting [11,28,29]. With no head-to-head comparisons for these agents, no predictive biomarkers in everyday clinical practice to guide treatment options, and no defined optimal treatment sequence, treatment decisions in the real-world are often based on disease behavior (progression and response to treatment), comorbidities, performance status, AE profiles of the treatments and patient preference. If patients do not respond to one hormonal therapy, then they may benefit from receiving cabazitaxel rather than an alternative hormonal agent. In the recent CARD study cabazitaxel significantly improved overall survival and other clinical outcomes over abiraterone or enzalutamide, with an acceptable safety profile, when given to patients with MCRPC who had previously received docetaxel and had progression with 12 months of treatment with the alternative hormonal agent (abiraterone or enzalutamide) [30]. Abiraterone and enzalutamide are often given after docetaxel, instead of cabazitaxel, because of the differing AE profile. In light of the CARD results, this post hoc analysis shows in a real-world clinical practice setting, across a large patient population, that cabazitaxel is well tolerated with associated AEs managed effectively and can be used in the elderly and frail patient populations.

In the pivotal cabazitaxel study, TROPIC, cabazitaxel improved survival and other clinical outcomes compared with mitoxantrone, despite the fact that $72 \%$ of patients receiving cabazitaxel had docetaxel-resistant disease (disease progression during prior docetaxel treatment or within 3 months of the last docetaxel dose) [11]. Cabazitaxel offers the chance for a response in patients with mCRPC who are resistant, or develop resistance to docetaxel.

Another field of interest for taxanes including cabazitaxel is in cancer that has an unknown primary origin. In a recent study (CUPISCO), analysis of 303 tissue samples with an unknown primary cause revealed that $32 \%$ could be treated with a molecularly targeted therapy [31]. However, in another study (GEFCAPI 04), where gene expression analysis was used to identify the most likely primary tumor, the best available targeted therapy and other treatments tailored to the primary tumor failed to improve disease progression or survival compared with chemotherapy [32]. For cancers of unknown primary origin taxanes are recognized as a chemotherapeutic option, so cabazitaxel could be a useful treatment option to be studied in these patients that have resistance to docetaxel $[33,34]$. Furthermore, it has been shown that patients with some specific subtypes of prostate cancer, such as luminal B (classified using gene expression signatures) experience significant improvements in time to castration resistance and overall survival following treatment with docetaxel plus androgen deprivation therapy (ADT) [35]. This biomarker analysis suggested that a novel genetic signature could be used to inform treatment decisions and select patients that may have improved responses to chemotherapy. In patients with the luminal B subtype who progress during or after treatment with docetaxel plus ADT, cabazitaxel could be an alternative therapeutic option.

\section{Materials and Methods}

\subsection{Study Designs and Treatment Protocol}

The study designs for CUP, EAP and CAPRISTANA are described in Figure 1. CUP, EAP and CAPRISTANA were international, multicenter, prospective registry studies. Across all studies, patients were scheduled to receive cabazitaxel $25 \mathrm{mg} / \mathrm{m}^{2}$ intravenously every 3 weeks plus oral prednisone or prednisolone $10 \mathrm{mg}$ daily. In the CUP and EAP studies, cabazitaxel was administered until disease progression, death, unacceptable toxicity, physician/patient decision, or the commercial availability of cabazitaxel (in some countries); in CAPRISTANA, patients were followed until death or up to 1.5 years (whichever came first) after initiation of cabazitaxel. In certain countries, the commercial availability of cabazitaxel, and also the availability of new treatments, may have resulted in the early discontinuation of cabazitaxel and removal of patients from the CUP and EAP studies. Study designs and treatment protocols have been described in detail previously for CUP, EAP and CAPRISTANA in their respective primary publications $[13,14]$. 


\subsection{Patient Population}

Key inclusion criteria across the studies included patients $\geq 18$ years of age with $\mathrm{mCRPC}$, previously treated with docetaxel, and scheduled to receive cabazitaxel. In addition, the CUP and EAP studies included patients that had a life expectancy of $>3$ months, an ECOG PS score of $\leq 2$, and adequate bone marrow, liver and renal function. The studies were conducted in accordance with the principles outlined in the Declaration of Helsinki (18th World Medical Assembly, 1964) and all its subsequent amendments. Each patient provided signed, written, informed consent before enrolment. Standard patient and disease characteristics, and treatment history were collected at baseline. For further details surrounding the inclusion and exclusion criteria for each trial, please see the previous publications $[13,14]$.

\subsection{Study Objectives and Endpoints}

The primary objective of the CUP and EAP studies was to allow access to cabazitaxel before its commercial availability in patients with $\mathrm{MCRPC}$ whose disease had progressed during or after docetaxel treatment; secondary objectives included assessment of the overall safety of cabazitaxel and in some countries health-related quality of life data were also collected. The primary objective of the CAPRISTANA study was to observe usage patterns of cabazitaxel; secondary objectives included further description of cabazitaxel usage patterns including subsequent therapies and use of G-CSF, clinical outcomes, health-related quality of life and safety. Results for the primary and secondary objectives of the CUP, EAP and CAPRISTANA studies have been previously published $[13,14]$. This manuscript presents a post hoc analysis with the objective of assessing the duration of cabazitaxel treatment in a real-world setting using data from the three registry studies.

\subsection{Safety Assessments}

Safety assessments included analysis of TEAEs and serious AEs (SAEs). A TEAE was defined as any untoward medical event or AE occurring or worsening during the on-treatment period (from the first administration of cabazitaxel to $\leq 30$ days after the last administration of cabazitaxel). A SAE was defined as any untoward medical occurrence or AE that resulted in death, was life threatening, required hospitalization, or resulted in persistent or significant disability/incapacity. AEs were graded according to the National Cancer Institute Common Terminology Criteria for Adverse Events, version 4.0 [36].

\subsection{Statistical Analyses}

Patient baseline characteristics, reasons for treatment discontinuation and disease progression were assessed according to cabazitaxel treatment duration ( $\leq$ median [6] vs. $>$ median [6] cycles, $\leq 4$ vs. $>4$ cycles and $1-2$ vs. $3-10$ vs. $\geq 11$ cycles); $P$ values were provided for comparisons between the different treatment groups (based on the number of cabazitaxel cycles received), using the Chi-Square test, Fisher's Exact test, Wilcoxon Mann-Whitney test or Kruskal-Wallis test. Odds ratios and confidence intervals were based on a logistic regression analysis.

\subsection{Cabazitaxel Treatment Cycles}

To assess cabazitaxel treatment duration and factors that may impact treatment duration in this post hoc analysis, subgroups of patients were defined and assessed according to the number of cabazitaxel treatment cycles they received: $\leq 6$ vs. $>6$ cycles; $\leq 4$ vs. $>4$ cycles; $1-2$ vs. $3-10$ vs. $\geq 11$ cycles. A cut-off of six cabazitaxel cycles were chosen because this was the median number of cabazitaxel cycles received in both the CUP/EAP and CAPRISTANA studies. Additionally, the identification and assessment of the subset of patients who discontinued cabazitaxel after $\leq 2$ cycles was of interest, as it was hypothesized that their main reason for cabazitaxel treatment discontinuation would most likely be due to tolerability issues. Incorporating the analysis of patients who discontinued after $\leq 4$ treatment cycles would therefore capture those patients discontinuing due to AEs but also those patients not responding to cabazitaxel treatment. Finally, the subset of patients who had a long duration 
of cabazitaxel treatment (i.e., beyond 10 cycles), were identified to assess whether any particular factors attributed to longer treatment duration.

\section{Conclusions}

This global, real-world post hoc analysis of pooled data from the CUP/EAP and CAPRISTANA studies further demonstrates the tolerability profile of cabazitaxel in a large population of patients and supports the use of cabazitaxel in patients with mCRPC after docetaxel, including patients who are elderly and/or frail. Some baseline characteristics may impact cabazitaxel treatment duration and discontinuation, and identification of these factors may help inform treatment decisions. Proactive and active management of AEs early in the course of cabazitaxel treatment may allow patients to receive a higher number of cabazitaxel cycles and derive a greater benefit.

Supplementary Materials: The following are available online at http://www.mdpi.com/2072-6694/12/4/995/s1, Table S1. Maximum number of cabazitaxel cycles received by patients in each country included in the CUP, EAP and CAPRISTANA studies and Table S2. Multivariate analysis of baseline characteristics associated with cabazitaxel treatment duration.

Author Contributions: Concept or design, E.E.-F. and A.O.; data acquisition, Z.M., A.P., G.D.L., U.D.G. and J.C.; data analysis or interpretation, all authors; review and editing, all authors. All authors have read and agreed to the published version of the manuscript.

Funding: This research was funded by Sanofi.

Acknowledgments: Editorial support was provided by Mohan Harihar and Danielle Lindley of MediTech Media, funded by Sanofi.

Conflicts of Interest: Z.M. is employed at the Clatterbridge Cancer Centre NHS Foundation Trust, which was involved in the EAP study in the United Kingdom. Z.M. has provided an advisory role, and has been part of speaker meetings, for Sanofi. U.D.G. has received consultant fees from Sanofi, Astellas, Bayer, Janssen, Bristol-Myers Squibb, Ipsen, Merck, Novartis and Pfizer. S.H., E.E.-F. and A.O. are employed by Sanofi. J.C. has provided an advisory role, and has been part of speaker meetings, for Bristol-Myers Squibb, Astellas, Bayer and Janssen. J.C. has also provided an advisory role for Merck, Sanofi and Roche, been part of speaker meetings for Asopharma Research and received research funding from Astellas. A.P. and G.D.L. have no conflicts of interest to disclose.

\section{References}

1. Ferlay, J.; Soerjomataram, I.; Dikshit, R.; Eser, S.; Mathers, C.; Rebelo, M.; Parkin, D.M.; Forman, D.; Bray, F. Cancer Incidence and Mortality Worldwide: Sources, Methods and Major Patterns in GLOBOCAN 2012. Int. J. Cancer 2015, 136, E359-E386. [CrossRef]

2. Kirby, M.; Hirst, C.; Crawford, E.D. Characterising the Castration-Resistant Prostate Cancer Population: A Systematic Review. Int. J. Clin. Pract. 2011, 65, 1180-1192. [CrossRef] [PubMed]

3. National Cancer Institute. Cancer Stat Facts: Prostate Cancer 2018. Available online: https://seer.cancer.gov/ statfacts/html/prost.html (accessed on 10 February 2020).

4. National Prostate Cancer Adult (NPCA). Second Year Annual Report - further Analysis of Existing Clinical Data and Preliminary Results from the NPCA Prospective Audit 2015. Available online: https: //www.npca.org.uk/content/uploads/2018/02/NPCA-2015-Annual-Report_FINAL_301115.pdf (accessed on 18 March 2020).

5. Varenhorst, E.; Klaff, R.; Berglund, A.; Hedlund, P.O.; Sandblom, G.; Scandinavian Prostate Cancer Group (SPCG) Trial No. 5. Predictors of Early Androgen Deprivation Treatment Failure in Prostate Cancer with Bone Metastases. Cancer Med. 2016, 5, 407-414. [CrossRef] [PubMed]

6. Amaral, T.M.; Macedo, D.; Fernandes, I.; Costa, L. Castration-Resistant Prostate Cancer: Mechanisms, Targets, and Treatment. Prostate Cancer 2012, 2012, 327253. [CrossRef] [PubMed]

7. Harris, W.P.; Mostaghel, E.A.; Nelson, P.S.; Montgomery, B. Androgen Deprivation Therapy: Progress in Understanding Mechanisms of Resistance and Optimizing Androgen Depletion. Nat. Clin Pract. Urol. 2009, 6, 76-85. [CrossRef] [PubMed]

8. Lorente, D.; Mateo, J.; Perez-Lopez, R.; de Bono, J.S.; Attard, G. Sequencing of Agents in Castration-Resistant Prostate Cancer. Lancet Oncol. 2015, 16, e279-e292. [CrossRef] 
9. Tannock, I.F.; de Wit, R.; Berry, W.R.; Horti, J.; Pluzanska, A.; Chi, K.N.; Oudard, S.; Theodore, C.; James, N.D.; Turesson, I.; et al. Docetaxel Plus Prednisone Or Mitoxantrone Plus Prednisone for Advanced Prostate Cancer. N. Engl. J. Med. 2004, 351, 1502-1512. [CrossRef]

10. Vrignaud, P.; Semiond, D.; Lejeune, P.; Bouchard, H.; Calvet, L.; Combeau, C.; Riou, J.-F.; Commercon, A.; Lavelle, F.; Bissery, M.-C. Preclinical Antitumor Activity of Cabazitaxel, a Semi-Synthetic Taxane Active in Taxane-Resistant Tumors. Clin. Cancer Res. 2013, 19, 2973-2983. [CrossRef]

11. de Bono, J.S.; Oudard, S.; Ozguroglu, M.; Hansen, S.; Machiels, J.P.; Kocak, I.; Gravis, G.; Bodrogi, I.; Mackenzie, M.J.; Shen, L.; et al. Prednisone Plus Cabazitaxel Or Mitoxantrone for Metastatic Castration-Resistant Prostate Cancer Progressing After Docetaxel Treatment: A Randomised Open-Label Trial. Lancet 2010, 376, 1147-1154. [CrossRef]

12. Gandaglia, G.; Bray, F.; Cooperberg, M.R.; Karnes, R.J.; Leveridge, M.J.; Moretti, K.; Murphy, D.G.; Penson, D.F.; Miller, D.C. Prostate Cancer Registries: Current Status and Future Directions. Eur. Urol. 2016, 69, 998-1012. [CrossRef]

13. Carles, J.; Pichler, A.; Korunkova, H.; Tomova, A.; Ghosn, M.; El Karak, F.; Makdessi, J.; Koroleva, I.; Barnes, G.; Bury, D.; et al. An Observational, Multicentre Study of Cabazitaxel in Patients with Metastatic Castration-Resistant Prostate Cancer Previously Treated with Docetaxel (CAPRISTANA). BJU Int. 2019, 123, 456-464. [CrossRef] [PubMed]

14. Malik, Z.; Heidenreich, A.; Bracarda, S.; Ardavanis, A.; Parente, P.; Scholz, H.; Ozatilgan, A.; Ecstein-Fraisse, E.; Hitier, S.; Di Lorenzo, G.; et al. Real-World Experience with Cabazitaxel in Patients with Metastatic Castration-Resistant Prostate Cancer: A Final, Pooled Analysis of the Compassionate use Programme and Early Access Programme. Oncotarget 2019, 10, 4161-4168. [PubMed]

15. Eisenberger, M.; Hardy-Bessard, A.C.; Kim, C.S.; Geczi, L.; Ford, D.; Mourey, L.; Carles, J.; Parente, P.; Font, A.; Kacso, G.; et al. Phase III Study Comparing a Reduced Dose of Cabazitaxel (20 mg/M2) and the Currently Approved Dose (25 mg/M2) in Postdocetaxel Patients with Metastatic Castration-Resistant Prostate Cancer-PROSELICA. J. Clin. Oncol. 2017, 35, 3198-3206. [CrossRef] [PubMed]

16. Caffo, O.; Maines, F.; Rizzo, M.; Kinspergher, S.; Veccia, A. Metastatic Castration-Resistant Prostate Cancer in very Elderly Patients: Challenges and Solutions. Clin. Interv. Aging 2016, 12, 19-28. [CrossRef]

17. Sanofi. JEVTANA®(Cabazitaxel) Injection, Summary of Product Characteristics, EMA; Sanofi-Aventis U.S. LLC: Toronto, ON, Canada, 2017.

18. Sanofi. JEVTANA®(Cabazitaxel) Injection, Prescribing Information; FDA. Revised; Sanofi-Aventis U.S. LLC: Toronto, ON, Canada, 2017.

19. Castagneto, B.; Stevani, I.; Bortolus, R.; Bearz, A.; Buosi, R.; Chimienti, E.; Guglielmi, A.; Guglielmini, P.; Santarossa, S.; Fratino, L. Weekly Cabazitaxel in Elderly Patients (EP) with Metastatic Castration Resistant Prostate Cancer (mCRPC) Progressing After Docetaxel Treatment: WeCabE, a Phase II Study. J. Clin. Oncol. 2018, 36, 300. [CrossRef]

20. Clement-Zhao, A.; Auvray, M.; Aboudagga, H.; Blanc-Durand, F.; Angelergues, A.; Vano, Y.A.; Mercier, F.; El Awadly, N.; Verret, B.; Thibault, C.; et al. Safety and Efficacy of 2-Weekly Cabazitaxel in Metastatic Castration-Resistant Prostate Cancer. BJU Int. 2018, 121, 203-208. [CrossRef]

21. ClinicalTrials.gov. Trial Evaluating the Safety of Two Schedules of Cabazitaxel in Elderly Men with mCRPC Previously Treated with Docetaxel (CABASTY). Available online: https://clinicaltrials.gov/ct2/show/ NCT02961257 (accessed on 20 March 2020).

22. Droz, J.P.; Albrand, G.; Gillessen, S.; Hughes, S.; Mottet, N.; Oudard, S.; Payne, H.; Puts, M.; Zulian, G.; Balducci, L.; et al. Management of Prostate Cancer in Elderly Patients: Recommendations of a Task Force of the International Society of Geriatric Oncology. Eur. Urol. 2017, 72, 521-531. [CrossRef]

23. Heidenreich, A.; Scholz, H.J.; Rogenhofer, S.; Arsov, C.; Retz, M.; Muller, S.C.; Albers, P.; Gschwend, J.; Wirth, M.; Steiner, U.; et al. Cabazitaxel Plus Prednisone for Metastatic Castration-Resistant Prostate Cancer Progressing After Docetaxel: Results from the German Compassionate-use Programme. Eur. Urol. 2013, 63, 977-982. [CrossRef]

24. Bracarda, S.; Gernone, A.; Gasparro, D.; Marchetti, P.; Ronzoni, M.; Bortolus, R.; Fratino, L.; Basso, U.; Mazzanti, R.; Messina, C.; et al. Real-World Cabazitaxel Safety: The Italian Early-Access Program in Metastatic Castration-Resistant Prostate Cancer. Future Oncol. 2014, 10, 975-983. [CrossRef]

25. Castellano, D.; Anton Aparicio, L.M.; Esteban, E.; Sanchez-Hernandez, A.; Germa, J.R.; Batista, N.; Maroto, P.; Perez-Valderrama, B.; Luque, R.; Mendez-Vidal, M.J.; et al. Cabazitaxel for Metastatic Castration-Resistant 
Prostate Cancer: Safety Data from the Spanish Expanded Access Program. Expert Opin. Drug Saf. 2014, 13, 1165-1173. [CrossRef]

26. Wissing, M.D.; van Oort, I.M.; Gerritsen, W.R.; van den Eertwegh, A.J.; Coenen, J.L.; Bergman, A.M.; Gelderblom, H. Cabazitaxel in Patients with Metastatic Castration-Resistant Prostate Cancer: Results of a Compassionate use Program in the Netherlands. Clin. Genitourin. Cancer 2013, 11, 238-250. [CrossRef] [PubMed]

27. Heidenreich, A.; Bracarda, S.; Mason, M.; Ozen, H.; Sengelov, L.; Van Oort, I.; Papandreou, C.; Fossa, S.; Hitier, S.; Climent, M.A.; et al. Safety of Cabazitaxel in Senior Adults with Metastatic Castration-Resistant Prostate Cancer: Results of the European Compassionate-use Programme. Eur. J. Cancer 2014, 50, 1090-1099. [CrossRef]

28. Fizazi, K.; Scher, H.I.; Molina, A.; Logothetis, C.J.; Chi, K.N.; Jones, R.J.; Staffurth, J.N.; North, S.; Vogelzang, N.J.; Saad, F.; et al. Abiraterone acetate for treatment of metastatic castration-resistant prostate cancer: Final overall survival analysis of the COU-AA-301 randomised, double-blind, placebo-controlled phase 3 study. Lancet Oncol. 2012, 13, 983-992. [CrossRef]

29. Scher, H.I.; Fizazi, K.; Saad, F.; Taplin, M.-E.; Sternberg, C.N.; Miller, K.; de Wit, R.; Mulders, P.; Chi, K.N.; Shore, N.D.; et al. Increased Survival with Enzalutamide in Prostate Cancer after Chemotherapy. N. Engl. J. Med. 2012, 367, 1187-1197. [CrossRef] [PubMed]

30. de Wit, R.; de Bono, J.; Sternberg, C.N.; Fizazi, K.; Tombal, B.; Wülfing, C.; Kramer, G.; Eymard, J.-C.; Bamias, A.; Carles, J.; et al. Cabazitaxel versus Abiraterone or Enzalutamide in Metastatic Prostate Cancer. N. Engl. J. Med. 2019, 381, 2506-2518. [CrossRef] [PubMed]

31. Ross, J.S.; Sokol, E.S.; Moch, H.; Mileshkin, L.; Baciarello, G.; Losa, F.; Beringer, A.; Thomas, M.; Foser, S.; Elvin, J.; et al. Comprehensive Genomic Profiling (CGP) of Carcinoma Of Unknown Primary Origin (CUP): Retrospective Molecular Classification of Potentially Eligible Patients (Pts) for Targeted or Immunotherapy Treatment (Tx) Using the Prospective Cupisco Trial's Criteria. Ann. Oncol. 2019, 30 (Suppl. 5), 934. [CrossRef]

32. Fizazi, K.; Maillard, A.; Penel, N.; Baciarello, G.; Allouache, D.; Daugaard, G.; Van de Wouw, G.; Soler, G.; Vauleon, E.; Chaigneau, L.; et al. A Phase 3 Trial of Empiric Chemotherapy with Cisplatin and Gemcitabine or Systemic Treatment Tailored by Molecular Gene Expression Analysis in Patients with Carcinomas of an Unknown Primary (Cup) Site (GEFCAPI 04). Ann. Oncol. 2019, 30 (Suppl. 5), 851. [CrossRef]

33. Losa, F.; Soler, G.; Casado, A.; Estival, A.; Fernández, I.; Giménez, S.; Longo, F.; Pazo-Cid, R.; Salgado, J.; Seguí, M.Á. SEOM clinical guideline on unknown primary cancer (2017). Clin. Transl. Oncol. 2018, 20, 89-96. [CrossRef]

34. Argentiero, A.; Solimando, A.G.; Brunetti, O.; Calabrese, A.; Pantano, F.; Iuliani, M.; Santini, D.; Silvestris, N.; Vacca, A. Skeletal Metastases of Unknown Primary: Biological Landscape and Clinical Overview. Cancers (Basel) 2019, 11, 1270. [CrossRef]

35. Hamid, A.; Wang, X.V.; Chen, Y.-H.; Feng, F.Y.; Den, R.B.; Attard, G.; Van Allen, E.M.; Huang, H.-C.; Karns, A.; Dittamore, R.; et al. Luminal B Subtype as a Predictive Biomarker of Docetaxel Benefit for Newly Diagnosed Metastatic Hormone Sensitive Prostate Cancer (Mhspc): A Correlative Study of E3805 CHAARTED. J. Clin. Oncol. 2020, 38 (Suppl. 6), 162. [CrossRef]

36. National Cancer Institute. Common Terminology Criteria for Adverse Events (CTCAE) Version 4.03. 2010. Available online: https://www.eortc.be/services/doc/ctc/CTCAE_4.03_2010-06-14_QuickReference_5x7.pdf (accessed on 16 March 2020).

(C) 2020 by the authors. Licensee MDPI, Basel, Switzerland. This article is an open access article distributed under the terms and conditions of the Creative Commons Attribution (CC BY) license (http://creativecommons.org/licenses/by/4.0/). 